Kitonde et al., Afr J Tradit Complement Altern Med. (2013) 10 (1):149-157

http://dx.doi.org/10.4314/ajtcam.v10i1.20

\title{
ANTIMICROBIAL ACTIVITY AND PHYTOCHEMICAL STUDY OF VERNONIA GLABRA (STEETZ) OLIV. \& HIERN. IN KENYA.
}

\section{Catherine Kadogo *Kitonde, Dossaji Saifuddin Fidahusein, Catherine Wanjiru Lukhoba and Miriam Musamia Jumba}

\author{
University of Nairobi, School of Biological Sciences, P.o. Box 30197- 00100, GPO, Nairobi. \\ Email: ckitonde@uonbi.ac.ke, ckitonde@yahoo.com
}

\begin{abstract}
Infectious diseases are prevalent and life threatening in Kenya. Majority of the sick are seeking herbal remedies in search of effective, safe, and affordable cure. This project aims to investigate the antimicrobial activity and presence of active phytochemical compounds in different parts of Vernonia glabra; a plant used by herbalists in various regions of Kenya, for the treatment of gastrointestinal problems. The plant sample was collected in January 2010 in Machakos, and different parts dried at room temperature under shade, ground into powder and extracted in Dichloromethane: Methanol in the ratio 1:1, and water. These crude extracts were tested against Staphylococcus aureus, Escherichia coli, Candida albicans, and Aspergillus niger for antimicrobial activity using disc diffusion technique. Minimum inhibitory concentrations (MICs) for active crude extracts were done using disc diffusion technique after the failure of agar and broth dilution methods. It was observed that the organic crude extracts of flower, leaf, stem, root, and/or entire plant, showed activity against at least one of the four micro-organisms screened, and at concentrations lower than the aqueous crude extracts. Organic crude extract of the leaf showed the highest activity against Staphylococcus aureus (mean inhibition zone of 1.85), recording higher activity than the commercially used standard antibiotic (Streptomycin mean inhibition zone of 1.30). The organic crude extract of flower showed significant activity only against $S$. aureus, with the lowest MIC of $1.5625 \mathrm{mg} / 100 \mu 1$, compared to streptomycin with M.I.C of $6.25 \mathrm{mg} / 100 \mu \mathrm{l}$. Thin Layer Chromatography-Bioautography Agar-Overlay showed that, flower alkaloids $(50 \%$ active), root sapogenins (43.8\% active), and root terpenoids $(38.5 \%$ active) were identified as the potential antibacterial compounds against $S$. aureus. These results suggest that, V. glabra contains phytochemicals of medicinal properties and justify the use of V. glabra in traditional herbal medicine for the treatment of microbial based diseases. However, research on toxicity which is missing in this study is recommended for V. glabra in order to verify, validate and document the safety of this medicinal plant to the society.
\end{abstract}

Keywords: Vernonia glabra, Antimicrobial activity, and Phytochemicals.

\section{Introduction}

Infectious diseases caused by microbes are a major health hazards all over the world, Jigna et al., (2007); Sasikumar et al., (2007). Throughout history, infectious diseases have been a major threat to human and animal health and a prominent cause of morbidity and mortality, WHO/FAO/OIE, (2003). The use of natural products with therapeutic properties is as ancient as human civilization and for a long time, mineral, plant and animal products were the main source of drugs. For centuries, people have used plants for healing, Maryam et al., (2010). About $80 \%$ of the worlds people rely on traditional plant based medicine, UNEP, (2010). Increased antibiotic resistance has become a global concern, coupled with the problem of microbial persistence, thus highlighting the need to develop novel microbial drugs that are not only active against drug resistant microbes, but more importantly, kill persistent micro-organisms and shorten the length of treatment. Apart from toxicity, lengthy therapy also creates poor patient compliance, Mariita et al., (2010). It is estimated that about $75 \%$ population in Kenya seeks health care among traditional healers, Sandiga et al., (1995). Traditional medicine is widely practiced in Kenya, where this has been documented by ethnomedical surveys, Miaron et al., (2004); Kareru et al., (2007).

The high cost of important conventional drugs and/ or inaccessibility to western health care facilities has led to overreliance on traditional medicine since it is affordable and available to people. On the other hand, even when western health facilities are available, traditional medicine is viewed as an efficient and an acceptable system from a cultural perspective, Munguti, (1997). Infections associated with bacterial and fungal pathogens are among some of the indications treated using traditional remedies in Kenya. Therefore, the aim of this project is to investigate the efficacy and phytochemical compounds present and active in different parts of V. glabra; an herb used by traditional practitioners in Kenya. A decoction of leaf plus root taken orally is claimed to treat gastrointestinal problems in Kenya Johns et al., (1995). The leaf ash or crushed leaves rubbed into scarification around the snake bite is used as antidote, Owour and Kisangau, (2006).

\section{Material and Methods}


Kitonde et al., Afr J Tradit Complement Altern Med. (2013) 10 (1):149-157

http://dx.doi.org/10.4314/ajtcam.v10i1.20

\section{Collection of Plant Material}

The plant was selected based on ethnomedicinal information from literature and collected from Kathiani village in Machakos county, Kenya in January 2010 which falls within the floral region K4 (Fig.1). The specimen was authenticated by a plant taxonomist in University of Nairobi and a voucher specimen (CK 2010/01) deposited at University of Nairobi Herbarium.

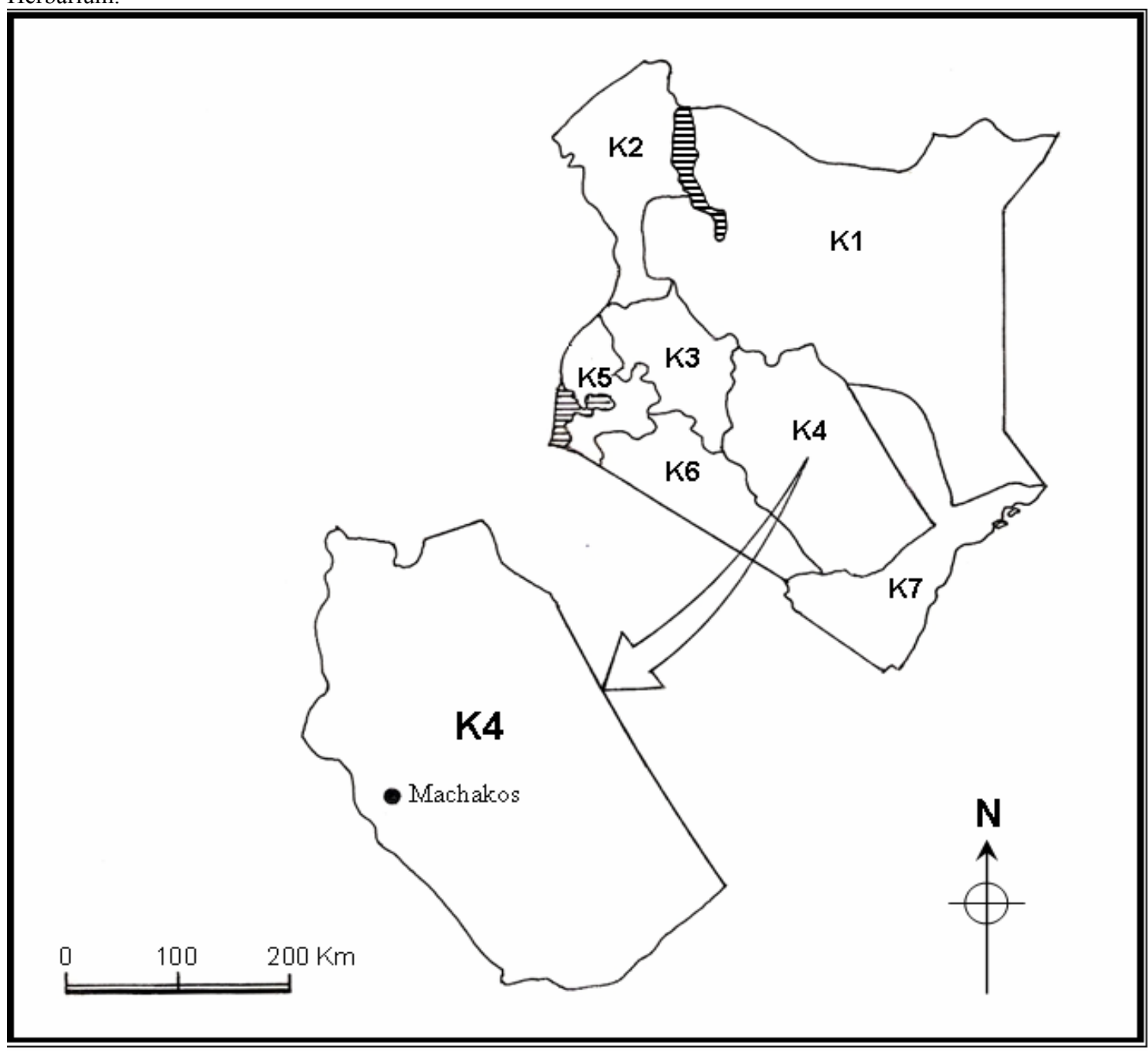

Fig. 1. A Map of Kenya showing Floral Regions of Kenya according to Flora of Tropical East Africa (FTEA) Beentje, (1994).

\section{Crude plant Extracts preparation}

The flowers, leaves, stem, and roots were air-dried under the shade at room temperature, ground into powder and extracted using Dichloromethane/Methanol in the ratio 1:1, and water, according to standard extraction methods (Harborne, 1998). $20 \mathrm{~g}$ of powdered plant material was mixed thoroughly with appropriate amount of solvent, left to stand for 24 hours and decanted (this was done twice). The filtrates were combined and filtered using a Buchner funnel. Dry organic crude extracts were obtained after evaporating Dichloromethane and Methanol using a rota evaporator. The aqueous extracts filtrates were dried into powder using a freeze drier. These were made up to desired concentrations for antimicrobial assay tests.

\section{Sources of Micro-organisms and Preparation of Standard inoculums}

Pure cultures of bacteria; Staphylococcus aureus ATCC 259213, Escherichia coli NC 35218 (from School of Pharmacy, University of Nairobi) were maintained on nutrient broth slants at $4^{\circ} \mathrm{C}$, while fungi; Candida albicans SC 5314 (from Seattle Biomedical Research Institute U.S.A), and Aspergillus niger ATCC 16404 (a collection of the late Professor George M. Siboe, University of Nairobi) were maintained on Sabourauds' Dextrose agar at $4^{\circ} \mathrm{C}$. The standard inoculums suspensions were adjusted to turbidity equivalent to $0.5 \mathrm{McF}$ arland standards to give a density of $1 \times 10^{8}$ cells or spores $/ \mathrm{ml}$ (Nostro et al., 2000). 
http://dx.doi.org/10.4314/ajtcam.v10i1.20

\section{Antimicrobial Activity}

Disc diffusion technique recommended by the National Committee for Clinical Laboratory Standards (NCCLS) was used. $2 \mathrm{ml}$ stock solution at concentration $2000 \mathrm{mg} / 2 \mathrm{ml}(1000 \mathrm{mg} / \mathrm{ml})$ was prepared for each plant part and entire plant used. Two fold serial dilutions were prepared from each stock solution. Paper discs were punched from Whatman filter paper No.1 using a paper punch. From each concentration prepared, $100 \mu 1$ were pipetted onto individually placed sterile paper discs $(0.6 \mathrm{~cm})$ on flat-bottomed glass plates drop by drop using a micropipette. The paper discs were allowed to dry before the release of the next drop, and kept under low temperatures waiting for antimicrobial assays. The potency of each paper disc per extract for the concentrations prepared was; $100 \mathrm{mg} / 100 \mu 1,50 \mathrm{mg} / 100 \mu 1,25 \mathrm{mg} / 100 \mu 1,12.5 \mathrm{mg} / 100 \mu 1,6.25$ $\mathrm{mg} / 100 \mu \mathrm{l}, 3.125 \mathrm{mg} / 100 \mu \mathrm{l}, 1.5625 \mathrm{mg} / 100 \mu \mathrm{l}, 0.78125 \mathrm{mg} / 100 \mu \mathrm{l}, 0.390625 \mathrm{mg} / 100 \mu \mathrm{l}$ and $0.1953125 \mathrm{mg} / 100 \mu \mathrm{l}$. Impregnated paper discs with crude extracts, were aseptically transferred onto plates inoculated with $1 \mathrm{ml}$ of standard inoculum for each test organism. The plates were labelled, sealed with parafilm, and incubated at $37^{\circ} \mathrm{C}$ for S. aureus, E. coli, C. albicans, and $25^{\circ} \mathrm{C}$ for A. niger. Streptomycin (for bacteria) and Nystatin (for fungi) were used as standards at similar concentrations, while discs with extraction solvents only were used as controls. These were done in duplicates under sterile conditions. The results were recorded after $24,48,72$ and 96 hours. The antimicrobial activity was determined by measuring clear inhibition zones diameters (including diameter of paper discs) formed using a transparent ruler (in $\mathrm{cm}$ ). Minimum inhibitory concentrations (MICs) were determined by recording the lowest concentration of the active extracts that inhibited growth of the micro-organisms (Ochei and Kolhatkar, 2000).

\section{Chemical Analysis of Selected Crude plant Extracts}

Extracts that exhibited MICs of $\leq 25 \mathrm{mg} / 100 \mu \mathrm{l}$ ) against any of the test-organisms used were selected for chemical analysis. They were screened for the presence or absence of five classes of compounds namely: alkaloids, Sapogenins, terpenoids, quinones, and flavonoids using Thin Layer Chromatography (TLC) technique. The developed TLC plates were viewed under Ultra-Violet light and then sprayed with appropriate reagents for the detection of the chemical groups according to Harborne (1998).

\section{Bioautography Agar Over-Lay}

The active compounds were identified using bioautography agar over-lay method on commercially prepared Aluminium silica gel TLC plates against only the most affected test-organism. The separated spots were observed under UV lamp and the freshly prepared standard inoculum of Staphylococcus aureus in nutrient agar was uniformly overlaid on the TLC plates with the crude extracts and incubated at $37^{\circ} \mathrm{C}$ for 24 hours, then sprayed with aqueous solution of $2.5 \mathrm{mg} / \mathrm{ml}$ thiazolyl blue (3-(4, 5 dimethylthiazolyl-2-2, 5-diphenyl tetrazolium bromide (MTT), Nostro et al., (2000); Runyoro et al., (2006) and inhibition zones noted.

\section{Data Analysis}

In order to analyse data, multiple way ANOVA was used to determine significant factors in formation of inhibition zones, Tukey's Honest Significant Difference Test (THSDT) was used for means comparison within the significant factors. Ms Word 2007 was used to draw tables; Ms Excel 2007 was used to determine means inhibition zones, percentage number of present and active compounds, and plotting of bar graphs.

\section{Results \\ The antimicrobial activity.}

The antimicrobial activity (formation of inhibition zones) of Vernonia glabra crude extracts depended on: (a) parts of plant used, (b) extraction solvent, and (c) test-organism factors (Table 1).

Table 1: Significance of Parts of plant used, Extraction solvent, and Test-organism in production of Inhibition zones

\begin{tabular}{|c|c|c|c|c|c|}
\hline 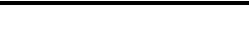 & $\overline{\mathrm{Df}}$ & Sum Sq & Mean Sq & F value & $\operatorname{Pr}(>\mathrm{F})$ \\
\hline Extraction Solvent & 1 & 5.610 & 5.6103 & 89.1855 & $<2.2 \mathrm{e}-16 * * *$ \\
\hline Parts of plant used & 4 & 1.985 & 0.4963 & 7.8902 & $2.612 \mathrm{e}-06 * * *$ \\
\hline Test-organism & 3 & 11.268 & 3.7560 & 59.7081 & $<2.2 \mathrm{e}-16 * * *$ \\
\hline Time & 3 & 0.066 & 0.0220 & 0.3492 & 0.7898 \\
\hline Residuals & 2068 & 130.089 & 0.0629 & & \\
\hline Signif. codes: & \multicolumn{5}{|c|}{ 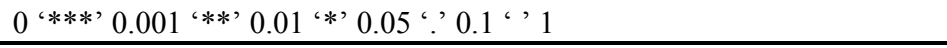 } \\
\hline
\end{tabular}

*Based on multiple-way ANOVA, part of plant used, test- organism, and extraction solvent factors were significant, but the time factor was not significant at statistical p-value $\leq 0.05$

Three factors namely: extraction solvent, parts of plant used, and test-organism were highly significant in the production of inhibition zones at $\mathrm{p}$-value $=0.00^{* * *}(0 \%$ error); less than the accepted statistical $\mathrm{p}$-value $\leq 0.05(5 \%$ error) in this study (see Table 1). The time factor (incubation period) was insignificant in that it has $p$-value $=0.7898$, greater than the accepted $p$ value $\leq 0.05$ ( $5 \%$ error) and therefore it was rejected. 
(a)Parts of plant used: In this study, mean inhibition zones were used as the results for figures 2,3 and 4 below. All the organic crude extracts of $V$. glabra parts used were active on at least one of the four test-organisms used (see Fig. 2). It was observed that organic extracts of V. glabra leaf had the highest activity (inhibition zone of 1.85) against S. aureus, followed by organic extract of flower with inhibition zone of 1.78 against only $S$. aureus. The two extracts showed no significant difference in activity from each other, but were significantly different in activity from streptomycin (inhibition zone of 1.30). Also organic extract of leaf recorded high activity (inhibition zone of 1.43) against A. niger, compared to nystatin (inhibition zone of 0.83), while the organic extract of whole plant (all parts mixed) showed significant activity (inhibition zone of 1.50) against $S$. aureus compared to streptomycin's (inhibition zone of 1.30) low activity.

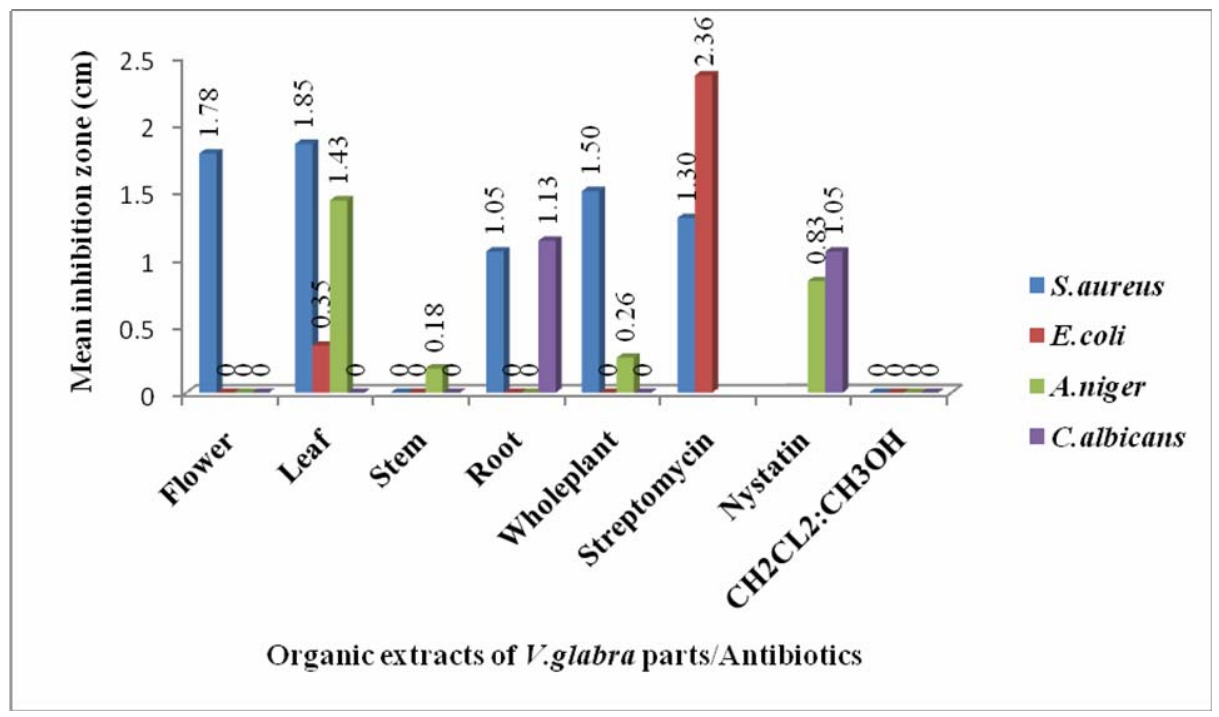

Figure 2: Antimicrobial activity of organic crude extracts of V. glabra parts compared to streptomycin and nystatin at 100 $\mathrm{mg} / 100 \mu \mathrm{l}$

Note: $\mathrm{CH}_{2} \mathrm{Cl}_{2}: \mathrm{CH}_{3} \mathrm{OH}$ - Dichloromethane and Methanol in the ratio 1:1(negative Control).

Aqueous extract of the whole plant of V. glabra was the only active aqueous extract against S. aureus (see Fig.3).

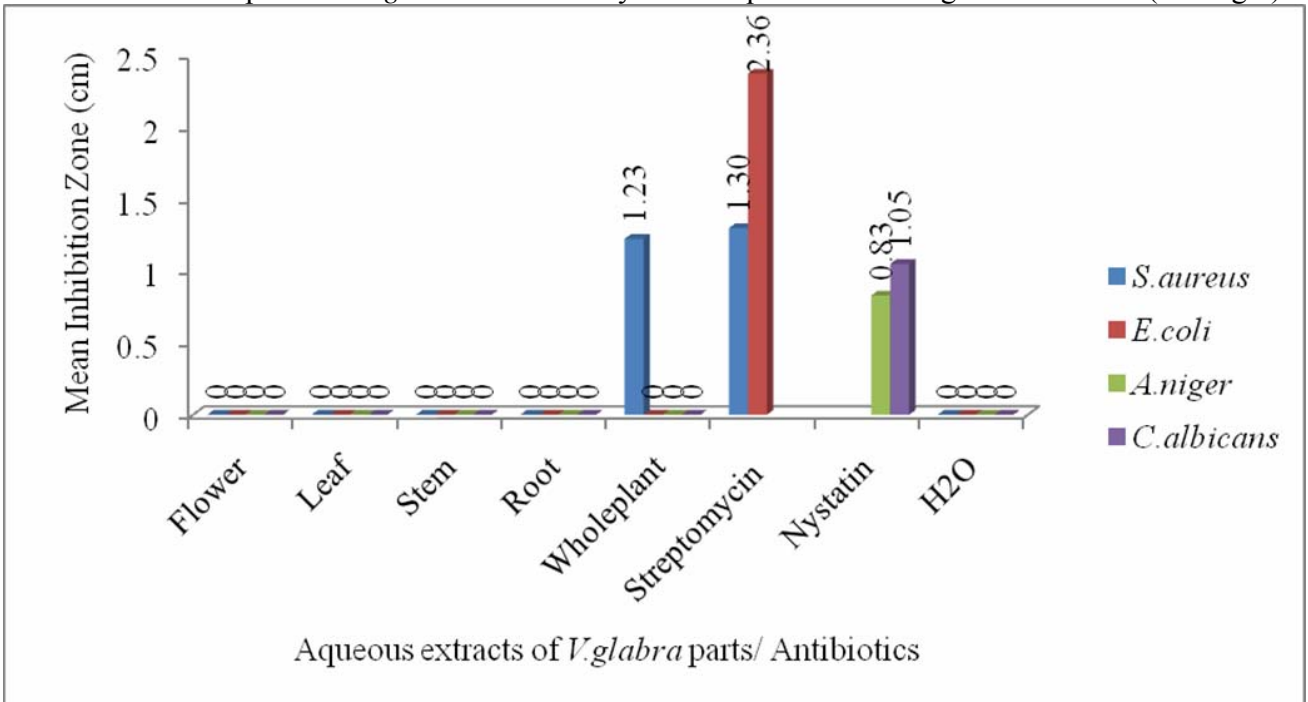

Figure 3: Antimicrobial activity of aqueous crude extracts of $V$. glabra parts compared to streptomycin and nystatin at 100 $\mathrm{mg} / 100 \mu \mathrm{l}$

The controls (Dichloromethane: Methanol 1:1, and sterile distilled water) were not active against any test-organism Note: $\mathrm{H}_{2} \mathrm{O}$ : Sterile distilled water (negative control).

(b) Extraction Solvent: The organic extracts of $V$. glabra were generally more active than the aqueous extracts most of which had lower activity or no activity against at least one of the four micro-organisms tested (Figure 4). 


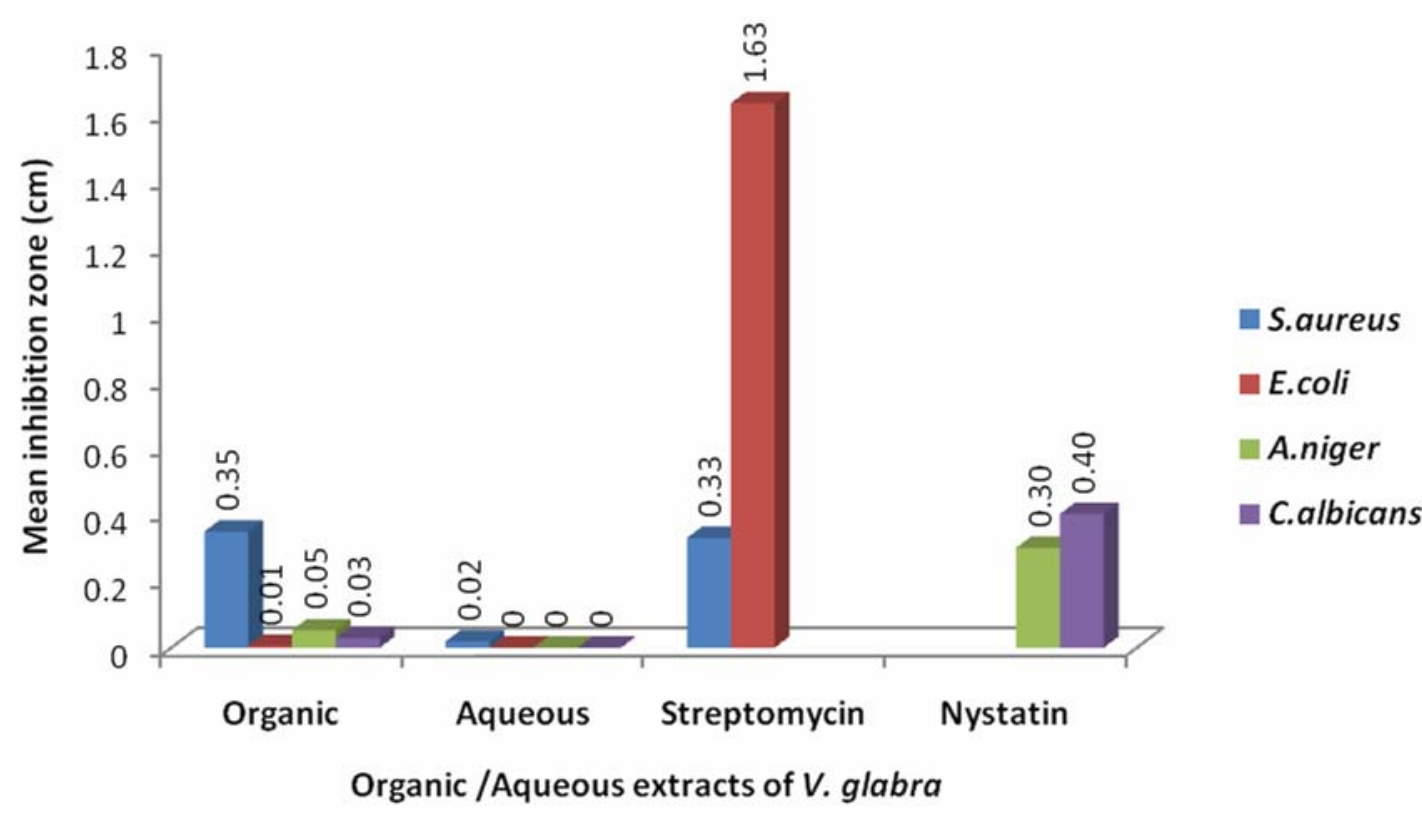

Figure 4: Organic versus aqueous crude extracts of $V$. glabra compared to streptomycin and nystatin at $100 \mathrm{mg} / 100 \mu \mathrm{l}$

(c).Test-organism: $S$. aureus was the most susceptible to organic extracts (inhibition of 0.35 ) and was significantly different in susceptibility from $A$. niger, C. albicans, and E. coli which had inhibition zones of $0.05,0.03$, and 0.01 respectively (see Fig. 4).

Minimum inhibitory concentration: MIC of each extract that was able to kill or inhibit the growth of at least one of the four micro-organisms tested in this study was exhibited by extracts that were active at concentration of $100 \mathrm{mg} / 100 \mu \mathrm{l}$ to $0.02 \mathrm{mg} / 100 \mu \mathrm{l}$. The lowest MICs $(1.5625-0.02 \mathrm{mg} / 100 \mu \mathrm{l})$ indicate highest activity, while $6.25-3.125 \mathrm{mg} / 100 \mu \mathrm{l}(\mathrm{moderate}$ activity), and 12.5-100 mg/100 $\mu 1$ indicate low activity (Table 2).

Table 2: MICs $(\mathrm{mg} / 100 \mu \mathrm{l})$ and Inverse of MICs $(\mathrm{mg} / 100 \mu \mathrm{l})$ of organic and aqueous extracts of V. glabra/Antibiotics against $S$. aureus, E.coli, A. niger, and C. albicans.

\begin{tabular}{|c|c|c|c|c|}
\hline Extract/Antibiotic & Test-organism & $\begin{array}{l}\text { MICs of } \\
\text { Extracts/Antibiotics } \\
(\mathrm{mg} / 100 \mu \mathrm{l})\end{array}$ & $\begin{array}{l}\text { Inverse of MICs } \\
(\mathrm{mg} / 100 \mu \mathrm{l})\end{array}$ & Remarks \\
\hline \multicolumn{5}{|l|}{ Organic extracts } \\
\hline Flower & S.aureus & 1.5625 & 0.64 & High activity \\
\hline \multirow[t]{2}{*}{ Streptomycin (Antibiotic) } & E. coli & $0.02+1$ & 0.98 & High activity \\
\hline & S. aureus & 6.25 & 0.16 & Moderate activity \\
\hline \multirow[t]{2}{*}{ Nystatin (Antibiotic) } & A. niger & 3.125 & 0.32 & Moderate activity \\
\hline & C. albicans & 3.125 & 0.32 & Moderate activity \\
\hline \multirow[t]{3}{*}{ Leaf } & S. aureus & 12.5 & 0.08 & Low active \\
\hline & E. coli & 100 & 0.01 & Low active \\
\hline & A. niger & 25 & 0.04 & Low active \\
\hline Stem & A. niger & 100 & 0.01 & Low active \\
\hline \multirow[t]{2}{*}{ Root } & S. aureus & 25 & 0.04 & Low active \\
\hline & C. albicans & 50 & 0.02 & Low active \\
\hline Whole plant & S. aureus & 25 & 0.04 & Low active \\
\hline \multicolumn{5}{|l|}{ Aqueous extract } \\
\hline Whole plant & S. aureus & 100 & 0.01 & Low active \\
\hline
\end{tabular}

Note*: $0.02+1-1$ was added to 0.02 in order to get a value that will minimize the big range among the inverse numbers, because values without whole numbers tend to have high inverse numbers. 
http://dx.doi.org/10.4314/ajtcam.v10i1.20

The inverse of MICs was displayed on fig. 5 below. Organic extract of flower showed highest activity recording the lowest MIC of $1.5625 \mathrm{mg} / 100 \mu \mathrm{l}$ against $S$. aureus, which was lower than the standard antibiotic (streptomycin) with MIC of $6.25 \mathrm{mg} / 100 \mu \mathrm{l}$. The organic extracts of root, whole plant against $S$. aureus, and leaf against A. niger and S. aureus had low activity (Fig. 5). The organic extract of root against $C$. albicans, organic extract of whole plant against $A$. niger, organic extract of stem against $A$. niger, and aqueous extract of whole plant against $S$. aureus, and organic extract of leaf against $E$. coli were less effective at higher concentrations (Figure 5).

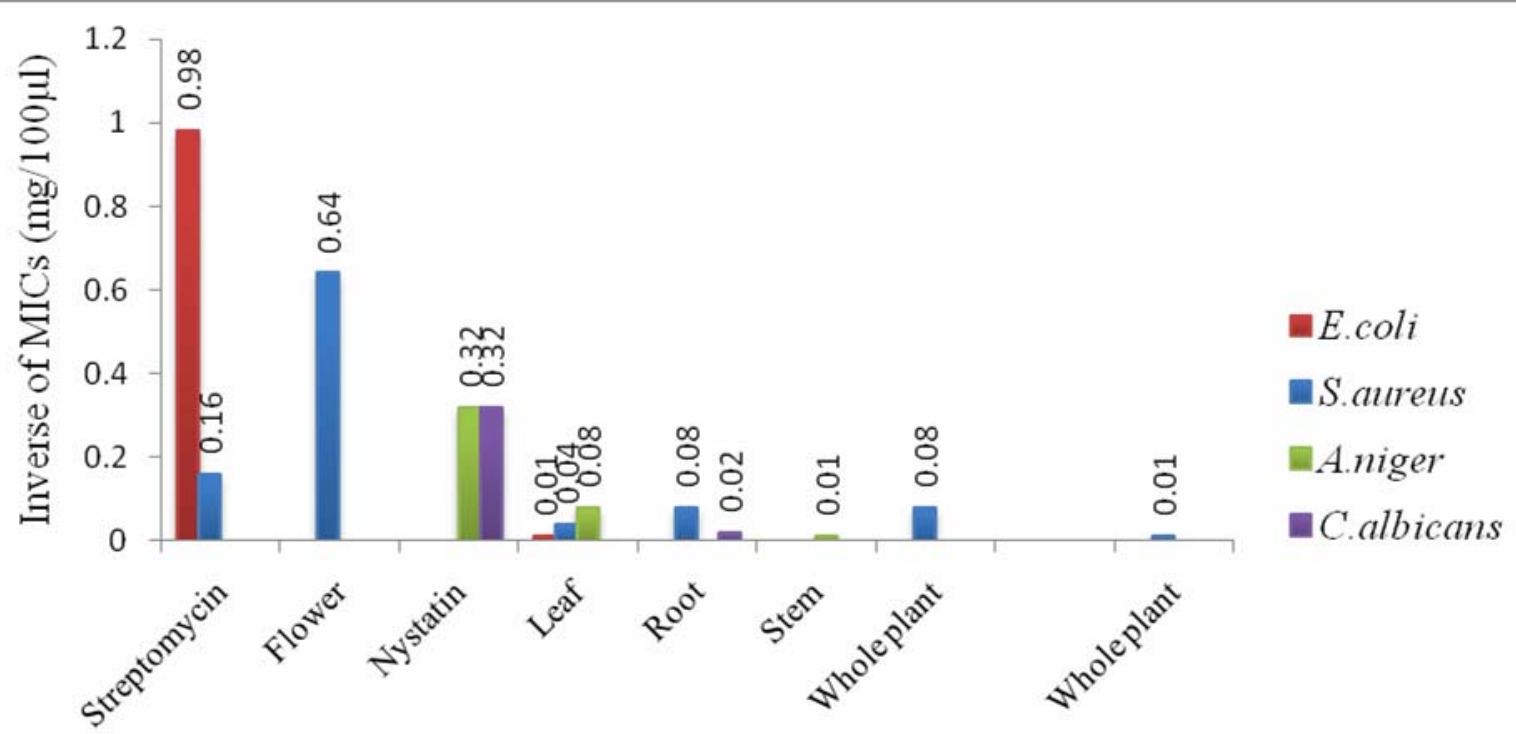

\section{Organic extracts of $\mathrm{V}$ glabra/Antibiotics $\quad$ Aqueous extract of $\mathrm{V}$.glabra}

Figure 5: MICs for organic and aqueous extracts of V. glabra compared to streptomycin and nystatin (antibiotics).

Note: Extracts/antibiotics with high inverse of MICs indicate higher activity (MIC 0.64-0.98 $\mathrm{mg} / 100 \mu \mathrm{l}$ ) at low concentrations, extracts/antibiotics with inverse of MICs of $0.16-0.32 \mathrm{mg} / 100 \mu 1$ indicate moderate activity, while the extracts with low inverse of MICs display low activity at higher concentrations (see Table 2).

Presence and Activity of Chemical Compounds. Out of all the alkaloids screened present in different parts, flower alkaloids were $50 \%$ present and all were active against $S$. aureus. Root sapogenins made up $43.8 \%$ of all sapogenins present and all were active, while flower sapogenins followed with $31.3 \%$ presence and all were active against $S$. aureus. Root terpenoids showed $38.8 \%$ presence out of all terpenoids and almost all of them $(38.5 \%)$ were active against $S$. aureus. Quinones of flower and leaf accounted for $37.5 \%$ presence, but only leaf quinones were moderately active at $25 \%$ activity, where as flower qiunones were less active at $12.5 \%$. Flower flavonoids were present at $36.4 \%$, while both leaf and root flavonoids showed $31.8 \%$ presence out of all flavonoids screened and found present in different parts, but all showed less activity of $9.1 \%$ against $S$. aureus (Figure 6 ).

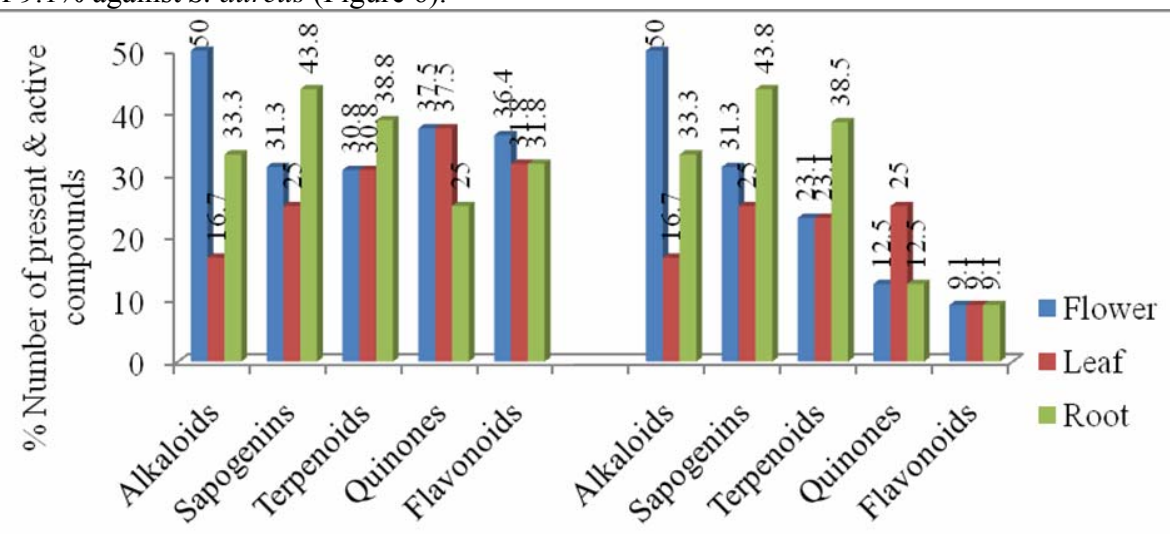

Classes of compounds present

Active classes of compounds

Figure 6: Percentage number of five classes of compounds present and active in V.glabra crude extracts (flower, leaf, and root).

Note*: Most of the alkaloids and sapogenins present in the different parts, and root terpenoids were active against S. aureus. Leaf quinones were moderately active, while all flavonoids in all different parts were less active. (fig.6). 
http://dx.doi.org/10.4314/ajtcam.v10i1.20

\section{Discussion}

The organic extracts of leaf (1.85) and flower (1.78) against S. aureus, had larger inhibition zones than the standard antibiotic (streptomycin 1.30). These results suggest that, these extracts could be used for management of bacterial diseases caused by Staphylococcus aureus such as boils, sores and wounds. The organic extract of leaf (1.43 against $A$. niger) showed high activity compared to nystatin (inhibition zone of 0.83 ). This signifies that, this extract could be used to produce novel antifungal compounds, for management of Aspergillosis disease caused by Aspergillus niger.

These results validate the use of V. glabra by traditional medicine practitioners in Kenya. The findings of this study are in agreement with the studies of Chika et al., 2007 who reported large inhibition zones of organic extracts of Euphorbia hirta leaf, against $S$. aureus, and justified its use by traditional medicinal practitioners for treatment of boils, sores and open wounds. Literature study done on V. glabra, elicited no previous research work on the antimicrobial activity of crude extracts of leaf and flower. As such, this could be the first report on such activity and could very well be a start point for further drug research of this species on a wide diversity of microbial pathogens.

Organic extracts of leaf against $E$. coli and root against $S$. aureus were less active compared to streptomycin, as well as extract of root against $C$. albicans and stem against $A$. niger compared to nystatin respectively. These findings could suggest presence of resistance of these test-organisms, and could be more active if the concentration of the extracts is increased. These findings are supported by Ochei and Kolhatkar, (2006) who reported that if drugs show less activity against microorganisms it is an indication of development of resistance by the test-organisms and that increase in drug concentration would increase the antimicrobial activity.

However, some of the crude extracts were not active against any of the four micro-organisms tested. For instance, organic extracts of flower (Fig.2) was not active against E. coli, A. niger, and C. albicans, while extract of stem was not active against $S$. aureus, E. coli, and C. albicans and no activity was exhibited by leaf extract against $C$. albicans respectively. These ineffective extracts, could have antimicrobial compounds active against diverse microbial pathogens that have not been worked on in this study. These findings correlate with the previous studies of Johns et al., 1995 who reported that decoction of V. glabra leaf and root was active against a non bacterial or non fungal micro-organism; Giardia lambria which is a protozoan.

Moreover, this study shows that there are synergistic, intermediate, and antagonistic effects among the plant parts used and their mixture. The organic extract of whole plant mixed (inhibition zone of 1.50 against $S$. aureus), showed intermediate activity ranging in between its highly active and less active single parts, yet traditional medicine prefer mixing (combining). This study may be an eye open for traditional medicine, and could indicate that, the interactions of active chemical substances present in single crude extracts of plant parts used, have strong synergistic effects to inhibit the growth of test-organisms, compared to their mixture with intermediate effect. This result could be due to antagonising effects of less active or inactive extracts, lessening the effect of highly active single crude extracts of $V$. glabra. These findings are in line with the findings of Maryam et al., (2010) who did research on different plant parts and mixtures (combinations) of plant extracts and found that, plant extracts or phytocompounds exhibiting strong antimicrobial activity may interact with each other and the interactions may be synergistic or antagonistic. Therefore, the synergistic effects of V. glabra leaf and flower extracts in this study would be of significant importance in further search of novel drugs, with desirable synergistic effects, to kill persistent micro-organisms that are resistant to known antibiotics and probably delay emergency of microbial resistance.

The organic extracts were active against S. aureus, A. niger, C. albicans, and E. coli with Mean inhibition zones of $0.35,0.05,0.03$ and 0.01 respectively. The aqueous extracts were less active against $S$. aureus only (Mean inhibition zone of 0.02 ) and inactive against E. coli, A. niger, and C. albicans. Noting that the traditional herbal remedy preparation from this species is by use of water, it is a paradox that the aqueous extracts were inactive in this study. This may be due to the absence or insufficient and effective concentration of the antimicrobial constituents in the aqueous extracts of V. glabra. These findings are in agreement with the studies of Koua et al., (2011) who reported that inactivity of aqueous and organic extracts of Striga hermonthica may be due to absence or insufficient and effective concentration of the antimicrobial agents of $S$. hermonthica extracts. It is well known that patients using the traditional herbs take in large amounts of the concoctions and hence may eventually consume sufficient amounts of the curative drugs to elicit healing.

Differential sensitivity of bacteria to V. glabra extracts may be explained by the cell wall composition of the grampositive and gram-negative bacteria. The cell wall of gram-ve bacteria (E. coli), contains the outer membrane and lipid bilayer embedded with proteins and porins that determine and allow different molecules or ions either into or out of the cell and thus the outer membrane serves as a barrier to the passage of many molecules and hence less sensitive to many extracts and render E. coli resistant to plant extracts. The gram+ve bacterium (S. aureus) has a relatively thick layer of peptidoglycan sheets of interconnected glycan chains made up of polymer which is fully permeable to many substances, and thus sensitive to most extracts, Nester et al., (2004).

Less effects of the crude extracts against C. albicans (yeast fungus) compared to A. niger (filamentous fungus) may also be due to differences in cell wall composition of the organisms. Yeast fungus cell wall contains polysaccharides and proteins, compared to chitin and glycan found in the cell walls of filamentous fungi, Paiva et al., (2010). The protein expression on C. albicans, function as selective transport system used to expel wastes and compounds that are otherwise deleterious to the cell; a function called efflux which is medically important in that, it allows micro-organisms to oust antimicrobial medications that are made to destroy them and therefore render them resistance, Nester et al., (2004). This explanation could be one of the reasons why C. albicans was resistant to most crude extracts. This observation reported in this study is in agreement with the findings of Masakazu et al., (2010), who did research on antifungal drug resistance of Candida spp and reported that expression of drug efflux pumps were responsible for the resistance.

The higher activity of organic extract of flower compared to the standard antibiotic (streptomycin) is significant. Such comparisons may be used as yardstick to identify novel drugs with new mechanisms of action to combat bacterial strains resistant to known antibiotics, shorten the length of treatment, increase patient compliance, and avoid overdose which 
may lead to toxicity or side effects to patients. The findings of this study are in line with the studies of Mariita et al., (2010); Aiyegoro and Okoth, (2009), who reported that bioactive extracts of medicinal plants at low concentrations are not only active against drug resistant bacteria, but kill persistent bacteria, shorten the length of treatment, reduce overdose and toxicity or side-effects.

The higher antimicrobial activity of Vernonia glabra flowers could be attributed to the presence of large amounts of flower alkaloids 50\% (Fig. 6). Alkaloids are pharmacogenically active basic principles of flowering plants, Das et al., (2010). The observed activity of these compounds in V. glabra is in line with that of Sawer et al., (2005) (as cited in Karou et al., 2006) who demonstrated that the Indoloquinoline alkaloid causes cell lysis and morphological changes of $S$. aureus. The presence of alkaloids in $V$. glabra extracts has not been reported in any previous research work and the findings in this study could be the first one to report. Root sapogenins (43.8\% present and active) have been associated with hemolysis property and it's probably why significant anti-staphylococcal activity has been reported in this study. This finding is in agreement with the studies of Pinarosa, et al., (2006) who did research on sapogenins of Medicago arabica root and reported a high anti-staphylococcal activity against $S$. aureus. According to literature on V. glabra sapogenins, no previous work has reported the presence of sapogenins in V. glabra. This could be the first time to report.

The antibacterial activity of root terpenoids $(38.5 \%$ active) may be due to presence of terpenes combined and associated with bacterial membrane disruption. This finding is in line with the studies of Chiruvella et al., (2007) who did research on terpenoids isolated from callus cultures of soymida febrifuga and reported that antimicrobial activity of terpenoids is probably due to membrane disruption by the terpenes. On the other hand, leaf quinones $(37.5 \%$ present but $25 \%$ active) had moderate activity, while flavonoids (31.8\% - 36.4\% present but $9.1 \%$ active) had low activity against $S$. aureus.

\section{Conclusion}

The screening of ten crude extracts ( 5 organic and 5 aqueous) of $V$. glabra collected using available ethnomedical information, has justified the medicinal potency in $V$. glabra used by traditional practitioners in Kenya to treat gastrointestinal problems and other different diseases. The ethnomedicinal information is important and can be used as a start point for research in drug development. The high activity of $V$. glabra flower reported at lowest MIC of $1.5625 \mathrm{mg} / 100$ $\mu 1$ than the standard antibiotic (streptomycin MIC of $6.25 \mathrm{mg} / 100 \mu \mathrm{l}$ ), is significant in treatment of resistant microbial pathogens. The low concentrations needed for treatment means that cases of overdose, toxicity, and side-effects may be reduced when using V. glabra flowers. However, research on toxicology which is missing in this study is recommended for $V$. glabra in order to verify and document the safety of this medicinal plant to the society.

\section{Acknowledgement}

This work was fully funded by the University of Nairobi, and partially ViCRES under the Inter-University Council of East African Universities (IUCEA). We gratefully thank them.

\section{References}

1. Aiyegoro, O.A., and Okoth, A.I. (2009). Use of bioactive plant products in combination with standard antibiotics: Implications in antimicrobial chemotherapy. Journal of Medicinal Plants Research, 3(13): 1147-1152.

2. Chiruvella, K.K., Mohammed, A., Dempuri, G., Gopal, R.G., and Raghavan, S.C. (2007). Phytochemical and Antimicrobial Studies of Methyl Angolensate and Luteolin of-O-glucoside Isolated from Callus Cultures of Soymida febrifuga. International Journal of Biomedical Science, 3(4): 269-278.

3. Chika, C.O., Jude, N.O., Ifeanyi, C.O., \& Anyanwu, N.B. (2007). Antibacterial Activities and Toxicological Potentials of Crude Ethanolic Extracts of Euphorbia hirta. Journal of American Science, 3(3): 11-16.

4. Das, K., Tiwari, R.K.S., \& Shrivastava, D.K. (2010). Techniques for Evaluation of Medicinal Plant Products as Antimicrobial Agent: Current Methods and Future Trends. Journal of Medicinal Plants Research, 4(2): 104-111.

5. Harborne, J.B. (1998). Phytochemical Methods: A Guide to Modern Techniques of Plant Analysis. $3^{\text {rd }}$ ed. London: Chapman \& Hall.

6. Jigna, P., and Chanda, S.V. (2007). In vitro Antimicrobial Activity and Phytochemical Analysis of Some Indian Medicinal Plants. Turkey Journal of Biology, 3: 53-58.

7. Johns, T., Faubert, G.M., Kokwaro, J.O., Mahunnah, R.L.A., \& Kimanani, E.K. (1995). Anti-giardial Activity of Gastrointestinal Remedies of the Luo of East Africa. Journal of Ethnopharmacology, 46 (1): 17-23.

8. Kareru, G., Kenji, M., Gachanja, N., Keriko, M., \& Mungai, G. (2007). Traditional Medicines among the Embu and Mbeere People of Kenya. African Journal of Traditional Complementary and Alternative Medicines, 4: 75-86.

9. Karou, D., Savadogo, A., Canini, A., Yameogo, S., Montesano, C., Simpore, J., ... Traore, A. (2006). Antibacterial activity of alkaloids from Sida acuta. African Journal of Biotechnology, 5(2): 195-200.

10. Koua, F.H.M., Babiker, H.A., Halfawi, A., Ibrahim, R.O., Abbas, F.M., Elgaali, E.I., ... Khlafallah, M.M. (2011). Phytochemical and biological study of Striga hermonthica (Del.) Benth Callus and intact plant. Research In Pharmaceutical Biotechnology, 3(7): 85-92.

11. Mariita, R.M., Ogol, C.K.P., Oguge, N.O., \& Okemo, P.O. (2010). Antitubercular and Phytochemical Investigation of Methanol Extracts of Medicinal Plants used by the Samburu Community in Kenya. Tropical Journal of Pharmaceutical Research, 9 (4): 379-385. 
12. Maryam, Z., Aqil, F., Khan, M.S.A., \& Ahmad, I. (2010). Ethnomedicinal plants derived antibacterial and their prospects. Ethnomedicine: A source of Complementary Therapeutics, 150-177.

13. Masakazu, N., Firth, N.A., Cannon, D.R. (2010). Antifungal drug resistance of oral fungi. Odontology, Review Article, 98(1):15-25. Available online: www.springerlink3.metapress.com [accessed $13^{\text {th }}$ September, 2011].

14. Miaron, O.J., Kassim, O., \& Ekaya, N. (2004). Indigenous Knowledge: The basis of Maasai Ethnoveterinary Diagnostic Skills. Journal of Human Ecology, 16: 43-48.

15. Munguti, K. (1997). Indigenous Knowledge in the Management of Malaria and Visceral Leishmaniasis among the Turgen of Kenya. Indigenous Knowledge Development Monitor, 5: 10-12

16. Nester, E.W., Anderson, D.G., Roberts, C.E., Pearsall, N.N., \& Nester, M.T. (2004). Microbiology: A Human Perspective. $4^{\text {th }}$ ed. New York. McGraw-Hill.

17. Nostro, A., Germano, M., Marino, D.V., \& Cannatelli, M. (2000). Extraction Methods and Bioautography for Evaluation of Medicinal Plant Antimicrobial Activity. Letters in Applied Microbiology, 30: 379-384.

18. Ochei, J., \& Kolhatkar, A. (2000). Medical Laboratory Science. Theory and Practice. India: Tata McGraw Hill, p.803.

19. Owour, B.O. and Kisangau, D.P. (2006). Kenyan Medicinal plants used as antivenin: a comparison of plant usage. Journal of Ethnobiology and Ethnomedicine, 2: 7.

20. Paiva, P.M.G., Gomes, F.H., Napoleao, T.H., Sa, R.A., Correia, M.T.S., \& Coelho, L.C.B.B. (2010). Antimicrobial activity of Secondary metabolites and Lectins from Plants Current Research, Technology and Education Topics in Applied Microbiology and Microbial Biotechnology, 396-406.

21. Pinarosa, A., Rosella, B., Tava, A., Vitali, C., Rosato, A., Zbigniew, B., ... Marian, J. (2006). Antimicrobial Activity of Sapons from Medicago sp: Structure-Activity Relationship. Phytotheapy Rearch, 20: 454-457.

22. Runyoro, D.K.B., Matee, M.I., Ngasapa, O.D., Cosam, C.J., \& Mwambo, Z.H. (2006). Screening of Tanzanian Medicinal Plants for Anti-Candida Activity. African Journal of Traditional, Complementary and Alternative Medicine, 6:11.

23. Sandiga, I., Chacha, C.N., \& Kanunah, M.P. (1995). Traditional Medicine in Africa: The existence and Use of Traditional Medicine in Kenya [e-book]. Nairobi: East African Educational Publishers Ltd. Available online: http://books.google.com/books [accessed $19^{\text {th }}$ July 2011].

24. Sasikumar, J.M., Thayumanavan, T., Subashkumar, R., Janardhanan, K., \& Lakshmanaperumalsamy, P. (2007). Antibacterial activity of some ethnomedicinal plants from the Nilgiris, Tamil Nadu, India. Natural Product Radiance, 6 (1): 34-39

25. United Nations Environment Program- UNEP. (2010). Global Strategy for Plant Conservation. Biodiversity is life 2010 International Year of Biodiversity. Online: www.cbd.int/gspc [accessed $13^{\text {th }}$ April, 2011]

26. World Health Organization, Food Agricultural Organization of the United Nations and World Organization for Animal Health- W.H.O/FAO/OIE. (2003). Expert Workshop on Non-human Antimicrobial Usage and Antimicrobial Resistance: Scientific Assessment, 1-5. 